\title{
Cinema: estratégia de ensino-aprendizagem na disciplina de história da enfermagem*
}

\author{
Cinema: teaching-learning strategy in the \\ discipline of nursing history
}

\section{Anna Maria Fornalski Tavares ${ }^{1}$ Liliana Müller Larocca ${ }^{2}$ Carmen Elizabeth Kalinowski ${ }^{3}$ Elizabeth Bernardino ${ }^{4}$}

Recebido em: 01/08/2013

Aprovado em: 19/10/2014

1 Acadêmica de Enfermagem da Universidade Federal do Paraná (UFPR). Bolsista do Programa de Iniciação à Docência (PID). Membro do Grupo de Pesquisas em Políticas, Gestão e Práticas em Saúde.E-mail: anna_mft@hotmail. com. Curitiba - PR.

2 Professora Adjunta da UFPR. Doutora em Educação. Orientadora do Programa Institucional de Bolsa de Iniciação à Docência. Membro do Núcleo de Estudos em Saúde Coletiva (NESC). Curitiba - PR.

3 Professora Adjunta da UFPR. Mestre em Enfermagem. Membro do Grupo de Pesquisas em Políticas, Gestão e Práticas em Saúde. Curitiba - PR.

4 Professora Adjunta da UFPR. Doutora em Enfermagem. Membro do Grupo de Pesquisas em Políticas, Gestão e Práticas em Saúde. Curitiba - PR.

\section{Resumo}

Considera-se neste estudo a dinâmica fílmica no contexto escolar como estratégia pedagógica na construção do conhecimento crítico, por meio da utilização do referencial teórico de Walter Benjamin, Marc Ferro e Marcos Napolitano. O objetivo geral foi expor o cinema, identificando ou não seus elementos verossímeis representados em determinados períodos históricos, de forma a motivar o público-alvo (os alunos) na apreensão da realidade concreta, estimulando então a reflexão, o raciocínio crítico e a autonomia intelectual.

Palavras-chave: Enfermagem. Cinema como Assunto. Tecnologia Educacional.

\begin{abstract}
Considered in this study the dynamics in the school context as filmic pedagogical strategy in building the critical knowledge, through the use of the theoretical framework of Walter Benjamin, Marc Ferro and Marcos Napolitano. The general goal was to expose the film, identifying whether or not your believable elements represented in certain historical periods, in order to motivate the target audience (students) in the apprehension of reality, stimulating the reflection, critical reasoning and intellectual autonomy.
\end{abstract}

Keywords: Nursing. Cinema as a Subject. Educational Technology. 


\section{Introdução}

Apesar de o cinema estar engajado nos meios culturais há pouco mais de uma centena de anos, este começou a ser usado como recurso didático na escola tempos depois. Contudo, houve um aproveitamento ideológico e de valores sociais, sendo respaldados mediante dinâmica de cultura transformadora desenvolvida (NAPOLITANO, 2010).

Ademais, vale destacar que a utilização de filmes, no âmbito acadêmico, permite estabelecer um diálogo variado, complexo, multidisciplinar, fora dos moldes e limitações impostos pela teoria, ou seja, há a promoção do debate em sala de aula, estimulando a reflexão e o raciocínio crítico, bem como a autonomia intelectual (NAPOLITANO, 2010).

Tais diálogos geram discussões capazes de externar as experiências pessoais dos alunos, propiciando um novo olhar do educando para o objeto de estudo. Destacamos, porém, que a prática "cinema em sala de aula" necessita de coordenação e planejamento do profissional docente para ser efetiva (NAPOLITANO, 2010).

Para tanto nos inspiramos nos estudos de Walter Benjamin e Marc Ferro, respectivamente, para reconhecer o cinema como agente de transformação cultural e a narrativa cinematográfica como produto cultural.

Nesse processo, temos como objetivo geral expor o cinema, identificando ou não seus elementos verossímeis representados em determinados períodos históricos, de forma a motivar o público-alvo (os alunos) na apreensão da realidade concreta.

Além disso, os objetivos específicos são os seguintes: motivar o estudante de Enfermagem à participação, aliar cinema/teoria, bem como desenvolver o perfil crítico e inovador deste. Dessa forma, o objeto deste estudo contemplou a utilização da produção fílmica como estratégia de ensino-aprendizagem para o estudante de Enfermagem.

\section{História versus produção fílmica no meio pe- dagógico}

No final do século XIX, dois irmãos franceses Louis e Auguste Lumière fizeram o que hoje conhecemos como a sétima arte, o cinema. O filme era composto por uma película com cenas "fotográficas" dispostas em maneira lógica e em movimento com velocidade constante, típicos do gênero do cinema mudo, muito próximo à realidade e com um profissional projetando-as em uma tela grande, o cinematógrafo. Outros pioneiros de referência no que concerne ao cinema como arte e entretenimento foram: os franceses Georges Meliès, Charles Pathè e Louis Galmont; e os ingleses James Williamson e George Smith (NAPOLITANO, 2010).

O trabalho com o cinema na pedagogia escolar tem como finalidade trazer à tona a representação fílmica com elementos verossímeis de determinados períodos históricos, incentivando o público-alvo na pesquisa histórica a fazer críticas e problematizar as questões distorcidas relacionadas à imagem representada, isto é, muitas representações fílmicas acabam projetando elementos contemporâneos de fatos históricos em suas películas, o que são conhecidos como anacronismos (NAPOLITANO, 2010).

Todavia, essa atividade prática, "cinema em sala de aula", para ser efetiva, requer que o professor coordene não só as escolhas dos filmes a serem trabalhados, mas também que participe ativamente na construção de raciocínio crítico dos alunos relacionando os temas envolvidos dos filmes com o conteúdo a ser discutido, personagens, valores históricos, políticos, existenciais em debates, bem como utilizar outras atividades na avaliação do aluno e do processo para a exploração desse raciocínio crítico (NAPOLITANO, 2010).

A escolha do filme então necessita ser pautada por planejamento, a fim de chegar à melhor organização da disciplina ministrada, com destaque para: o lugar em que o filme ocupa na história, bem como a cultura geral e audiovisual da turma. Assim, a atividade didática com o cinema poderá ser realizada com um roteiro de análise no horário da aula com o filme na íntegra ou em partes, ou extraclasse como atividade em grupos de alunos previamente formados pelo professor (NAPOLITANO, 2010).

$O$ roteiro de análise em questão serve para subsidiar e situar o tema abordado em aula com o intuito de ser informativo ou interpretativo, objetivando trazer à tona o maior interesse do aluno nessas atividades dinâmicas. Um roteiro informativo faria com que o aluno procurasse as partes técnicas da produção fílmica: nome do diretor, nacionalidade, ano de produção, nome dos autores, gênero e tema central, sinopse da história, lista dos personagens principais, suas características e funções dramáticas (NAPOLITANO, 2010).

Já no roteiro interpretativo, este vai além da parte 
técnica, agregando à ficha técnica do filme uma análise em que o aluno irá desenvolver seu raciocínio crítico diante do material cinematográfico na reconstituição prévia da história. Sendo assim, o professor poderá desenvolver uma gama de questões assertivas ou interrogativas com relação às características mais importantes do filme a ser trabalhado, relacionado ao conteúdo ministrado expositivamente, e objetivando a maior assimilação de conteúdo do aluno, realizado conforme o planejamento do professor, a fim de otimizar o trabalho com a produção fílmica (NAPOLITANO, 2010).

Se no planejamento do professor não estiver incluso a atividade fílmica em grupo, o mesmo poderá promover um debate individual em classe acerca do filme. Entretanto, os alunos mais extrovertidos ou mais experientes, maduros, podem roubar a cena e os mais introvertidos acabarem por não terem a sua participação ativa, efetiva (NAPOLITANO, 2010).

Então, cabe ao professor realizar esse debate de modo mais democrático, provocando os alunos menos participativos a realmente entrarem no debate. Outro contratempo que pode ocorrer em classe seria o nível de discussão chegar a um ponto de "achismos", em que o professor necessita ser o mediador e articulador das discussões, a fim de evitar esse nível de discussão, o que, com bom senso no trabalho com o cinema, em paralelo com a faixa etária dos alunos, a priori, resolve a questão (NAPOLITANO, 2010).

Contudo, é de parecer da pesquisadora Arlene Keeling (2001.) que a História da Enfermagem tem uma ampla gama no que confere à identidade profissional. Em suma, à medida que se conhece a história de uma profissão, como no caso a de Enfermagem, percebe-se sua importância na vida, no campo da saúde, assim como em relação aos seus compromissos sociais. É com esse raciocínio que a história deixa brechas a fim de delinear e identificar quem são, o que pensam, o que sentem, como agem as enfermeiras e, ainda, quais as perspectivas relacionadas ao que enfrentarão ao longo da vida como um grupo profissional antenado (PADILHA; BORENSTEIN; SANTOS, 2011)

Por sua vez, a Enfermagem quando estuda a sua história, necessariamente incorpora e se aproxima da interdisciplinaridade, não somente com relação ao historiador, mas também: antropólogo, sociólogo, psicólogo, filósofo, entre outros; pois, sem estes, não há possibilidades de uma compreensão dos processos históricos da construção dessa profissão (PADILHA; BORENSTEIN; SANTOS, 2011).

\section{Influências positivas do contexto fílmico em sala de aula}

Segundo a literatura, há profissionais que estão diretamente envolvidos com a questão escola/cinema pautados por livros que auxiliam na melhor utilização didática do cinema em sala de aula, tais como: "Filmes para ver e aprender", "A história vai ao cinema", "Como usar o cinema na sala de aula" (PEREIRA, 2011).

$\mathrm{Na}$ aprendizagem acadêmica dos enfermeiros, por exemplo, o filme também se aplica como recurso estratégico pedagógico, na medida em que desenvolve o perfil crítico e inovador do estudante, bem como a maior participação dos alunos, isto é, é um artefato dinâmico, constituído de entendimento do conteúdo fílmico por meio da teoria, que permite a experienciação dos universitários em práticas sociais e culturais (SILVA; SANTOS, 2009; TOURINHO; VIEIRA, 2011).

Outra concepção da utilização didática do filme com o público discente condiz com a estratégia da racionalização, ação pela qual os acadêmicos passam pelo processo de aprendizagem interiorizando a prática construída teoricamente não só pelo professor, mas também pelo conteúdo fílmico que pode abordar conceitos nunca antes visto. Na medida em que a obra fílmica traz à tona uma aprendizagem não conhecida, agregada ao coletivo, com interesse comum e uniforme, ela se torna benéfica no desenvolvimento do aluno e ajuda este a lidar com diversas situações (SILVA; SANTOS, 2009).

Portanto, a produção fílmica, utilizada como recurso estratégico de ensino-aprendizagem para o estudante, torna-se a imagem da teoria e da prática de Enfermagem, motivada por uma atenção maior em aprender a pensar, principalmente quando estiverem no ambiente da assistência hospitalar, em que poderão se defrontar com dificuldades na atuação e contato com os pacientes (SILVA; SANTOS, 2009).

Há também a possibilidade de avaliar com mais afinco as questões éticas relacionadas ao cuidado de saúde prestado aos indivíduos, o que permite desenvolver a tomada de decisão. Então, a produção fílmica pode proporcionar esse debate, que é experienciado estimulando a avaliação crítica e o entendimento efetivo das narrativas e necessidades particulares dos pacientes, ou seja, o uso 
do cinema nos eventos bioéticos forma uma feliz estratégia de ensino-aprendizagem de humanização ao abordar problemas morais, como aqueles referentes à eutanásia, ao direito à vida, rompendo com as barreiras do aprendizado tecnicista, alienado (DANTAS; MARTINS; MILITÃO, 2011).

Então, a tecnologia cinematográfica é um fator favorável à estratégia pedagógica, é inovadora, e transformadora na medida em que nos faz repensar, refletir nas atitudes que podem ser apreendidas no mundo fictício e transferi-las ao mundo real de maneira crítica e humanizada. No que se refere ao professor, estudar os fatos e simbologias que estão por trás da produção fílmica corresponderia a atuar pedagogicamente de forma efetiva nos dias atuais (FISCHER, 2007).

Um treinamento viável para futuros enfermeiros, por exemplo, no exercício de transmitir notícias desagradáveis aos pacientes e acompanhantes seria usar a produção fílmica, visto como uma estratégia comunicacional, que filtrando as imagens, pode-se usá-las como exemplo de instrução, bem como ser uma ponte no desenvolvimento de debates e discussões em pequenos grupos. Assim, novamente a produção cinematográfica é utilizada como estratégia de ensino-aprendizagem (TAPAJÓS, 2007).

Em suma, reforçando que a produção cinematográfica quando bem utilizada, ou seja, com a finalidade de transmitir conteúdos verossímeis do passado, fortalece o aprendizado escolar como forma de construção da aprendizagem histórica, consciência histórica, que na verdade é o objetivo do ensino da história (ABUD, 2003).

Em meados da década de 1930, o filósofo Walter Benjamin foi um dos pioneiros a pensar o cinema como arte, por isso Benjamin é um dos autores referência para a elaboração do presente estudo. Benjamin acreditava que o cinema era um instrumento de transformação cultural, sendo a arte a serviço do aprendizado, na medida em que transforma os sujeitos antes alienados em sujeitos pensantes. Em resumo, Benjamin dizia que: "[...] o valor histórico do cinema como a arte é sua capacidade em transformar a história” (MARTINS et al., 2008, p. 07).

Sabendo que, de certa maneira, um dos modos de se adquirir experiência na Enfermagem pode ser pautada em recursos midiáticos, Walter Benjamin (2002) diz que: "a máscara do adulto chama-se experiência”; recorremos, então, na escola (assim como no ensino superior) o cinema como forma de se obter "experiência" docente, com a prática fundamentada na teoria (MORAIS, 2004).

O historiador Marc Ferro na década de 1970 realizou estudos utilizando filmes como fonte histórica, reconhecendo a narrativa fílmica como não aleatória. Contudo, fazendo uma análise profunda do filme e considerando a linguagem cinematográfica deste, pode-se fazer um recorte daquilo que o filme quer passar a quem está assistindo, e também verificar determinados anacronismos (MARTINS et al., 2008, p. 07).

Marc Ferro (2010) salienta que: “[...] o cinema é um instrumento do progresso científico", utilizado tanto no militarismo (como propaganda do poderio bélico do armamento do inimigo) quanto nas ciências da saúde (com o objetivo de se retratar como se deu o processo de cuidado ao longo dos tempos).

Ferro (2010), então, reitera que o contexto do filme é extremamente relevante, ao passo que o tempo que se pretende mostrar neste não necessariamente é o tempo no qual se originou (PEREIRA, 2011).

\section{E enfim as cortinas se abrem para a história do cuidar a partir de obras cinematográficas}

Mesmo reconhecendo a não linearidade histórica, optamos por apresentar uma sequência de filmes que contribuem para uma aproximação à história do cuidado humano e da própria Enfermagem.

No que se refere ao cuidado à época do homem primitivo, como pode ser visto no filme A guerra do fogo (1981) segundo a literatura, há conexão com a necessidade da sobrevivência. Então, pode-se dizer que este baseava-se no instinto, fazendo com que o homem primitivo observasse os animais, descobrindo que eles quando feridos lambiam suas feridas - para aliviar a dor e eliminar as infecções -, comiam ervas - que têm função purgativa e emética -, submergiam as lesões nas águas, entre outros. Nesse momento o homem das "cavernas" começa a relacionar a doença com efeitos sobrenaturais ambientais, que só seriam convertidos em cura por meio de ritos e encantamentos (PADILHA; BORENSTEIN; SANTOS, 2011; OGUISSO, 2007).

Posteriormente, com o ser humano já vivendo em grupos sociais ampliados, este foi paulatinamente mesclando-se em povos com culturas diferenciadas, tais como: modo de vida, crenças religiosas e filosóficas. Os egípcios, por exemplo, e o processo de mumificação versus imortalidade, como verificado por meio do filme 
Cleópatra (1963), deixaram diversos tratados de saúde em papiros. Padilha, Borenstein e Santos (2011) expõem e analisam que houve um resultado positivo em toda a complexidade envolvida nesse processo (mumificação): a realização atual de estudos para a descoberta de diversas patologias, bem como entender o processo de bandagem com ataduras.

No que se refere ao papel da mulher na antiguidade, destacamos o filme Alexandria (2009). Padilha, Borenstein e Santos (2011) escrevem que as amas de leite amamentavam as crianças e eram, provavelmente, as principais responsáveis pelos cuidados aos doentes em casa. Contudo, as parteiras já eram mais reconhecidas; atendiam a partos normais, até os da realeza. Há gravuras e pinturas esboçando como eles ocorriam, quase sempre era empregada a prática de mulheres assistindo mulheres.

Assim como é reiterado por Padilha, Borenstein e Santos (2011), não há menção em documentos da existência de hospitais, nem de enfermeiros em específico, mas sim de outros profissionais que faziam a prática do cuidado: sacerdotes, médicos, entre outros profissionais. Entretanto, há fortes indícios de que havia locais que abrigavam e tratavam os doentes (alojamentos, templos), baseado em seu conhecimento no que concerne ao preparo e ação terapêutica de drogas (decocção, infusões, soluções para injeção, comprimidos, loções, pomadas, emplastros etc.). Os egípcios ainda faziam: controle sanitário, da higiene do corpo, da comida, das bebidas, das relações sexuais, das roupas, de matadouros, da água.

Já os palestinos (hebreus) têm sua história enunciada na Bíblia, deixando como legado o Código de Hammurabi - no qual havia regulamentação de cuidados quanto à saúde pública geral. Há citações de que as amas de leite eram cuidadoras dos enfermos. Todavia, as parteiras judias eram importantes, pois orientavam os cuidados de higiene das mães e de seus bebês, além de estimularem o parto de cócoras (realizado em um tamborete de forma circular). Tratando-se desse tema, Padilha, Borenstein e Santos (2011) relatam que Débora é a primeira enfermeira (cuidadora) citada na história (BIBLIA, 1982).

A literatura traz a figura do enfermeiro na Babilônia como um profissional liberal, com práticas parecidas com as atuais, porém há estudos convergindo para a possibilidade de serem trabalhadores domésticos ou escravos. Havia também relatos sobre as amas de leite e as parteiras (PADILHA; BORENSTEIN; SANTOS, 2011).

Entretanto, de 1200 a. C. em diante (até 612 a. C.) os assírios se sobressaíram em relação aos babilônicos, no que tange ao cuidado com os doentes, mesmo com as doenças relacionadas a castigos pelo pecado, assim como a cura, se concretizando por meio do arrependimento. Com relação ao cuidado, não há citações sobre a existência do enfermeiro, muito menos sobre hospitais (PADILHA; BORENSTEIN; SANTOS, 2011).

Segundo Padilha, Borenstein e Santos (2011), há descrição de princípios e práticas de Enfermagem em documentos indianos, realizado em hospitais por homens. Esse povo acreditava que a contração de doenças acontecia mediante "impureza" dos líquidos corporais ou que, em determinados eventos (como partos, por exemplo), o cuidado era prestado por idosas. Eles deveriam seguir um padrão em suas práticas, de forma que inspirasse confiança e cooperação. Os hindus já detinham o conhecimento farmacológico, e sabiam de sua relevância em sociedade.

Padilha, Borenstein e Santos (2011) analisam que ser enfermeiro havia certos requisitos, tais como: asseio, habilidade, inteligência, conhecimento de culinária e de preparo de remédios. Quanto aos médicos, os mesmos prestavam um juramento, a fim de garantir, por exemplo, que eles tratariam não só de ricos, mas também de pobres, de maneira igualitária, em uma eventual enfermidade. Ademais, esses profissionais eram preparados para saber fórmulas e orações aos deuses da vida, da morte e da saúde, sendo que o conhecimento prático era ínfimo, apenas simulavam as operações em: folhas, cascas de árvores, frutas e bonecos de argila.

De acordo com a literatura, se havia enfermeiros na China, estes não eram mulheres. Para estes quem cuidasse de enfermos por meio do toque poderia ficar impuro. Quanto aos hospitais, eram conhecidos por "casas de benevolência ou compaixão", ou "casas de cura". Os chineses, assim como Hipócrates com seus princípios, estudavam os desequilíbrios do indivíduo e sua relação com o ambiente, a fim de reorganizar os sistemas (PADILHA; BORENSTEIN; SANTOS, 2011).

$\mathrm{Na}$ Roma antiga o cuidador propriamente dito não aparece de forma objetiva, porém há relatos de que toda a história da civilização foi amparada por procedimentos médicos (baseado em uma mistura de práticas populares, magia e religião) e de Enfermagem, principalmente, segundo Padilha, Borenstein e Santos (2011), no ano de 293 a. C., época em que a peste devastou Roma e os médicos gregos (escravos) cuidavam dos enfermos romanos.

Reiterado por Padilha, Borenstein e Santos 
(2011) e Ribeiro (2008), Galeno, por exemplo, médico particular dos imperadores Marco Aurélio e Lúcio Vero teve sua contribuição nesse meio, por formular e prescrever substâncias farmacológicas (por isso adotou-se a terminologia "formulações galênicas", sendo então considerado o Pai da Farmácia), e cuidados com enfoque aos militares durante as guerras nos hospitais de campanha. Ademais, nesse período houve uma contribuição considerável, por parte da sociedade romana, para o progresso do conhecimento prático das enfermeiras.

Seguindo esse raciocínio, também é de parecer de Padilha, Borenstein e Santos (2011) e Ribeiro (2008), que o doutor grego Aulo Cornelius Celso estudou ferimentos de guerra, descrevendo então o desencadeamento com etapas do processo inflamatório, bem como seus sinais flogísticos: rubor, tumor, calor e dor (e no caso de calor e dor: enrijecimento e inchaço).

De acordo com Padilha, Borenstein e Santos (2011), o serviço médico público romano foi colocado em vias de uso no século IV d. C., mas a maioria da população não tinha esse acesso. Então, esta adoecia, curava-se, voltava a adoecer e a se recuperar apenas com a intervenção de um autotratamento, indicado pelo paterfamilias (alguém da família que os cuidava por meio de ervas e "mantras"), um hábito altamente comum, principalmente dos plebeus.

Os tratamentos aos doentes eram baseados na observação empírica das causas e dos efeitos. O aborto, por exemplo, era proibido, e este só era realizado por parteiras e médicos que só se interessavam em atuar se houvesse lucro financeiro; e, como não existiam técnicas para realizar a anestesia, esse profissional ajudava os mais abastados a encerrar a vida (eutanásia), enquanto os menos abastados acabavam se suicidando, pela falta de cuidado médico (PADILHA; BORENSTEIN; SANTOS, 2011).

Em sintonia com Padilha, Borenstein e Santos (2011) e Vieira (2008), a saúde pública incluía o saneamento básico, desenvolvimento e fornecimento de água limpa e potável (que beneficiava somente os mais abastados, patrícios); o abastecimento dessa água ocorria por meio de nove aquedutos, gastando cerca de três milhões de litros de água diariamente. Além disso, há relatos da existência de 800 banhos públicos na cidade, que além de conter piscinas de água quente, também possuíam saunas, banhos de assento, entre outros, com massagistas profissionais chamados iatraleptae.

Segundo Vieira (2008), a água da chuva era reutilizada na fabricação de remédios. A coleta de lixo era feita regularmente, a rede de esgotos era ótima, inclusive usada atualmente. Como medida de saúde pública, havia a vigilância nas construções, assim como a promoção da saúde das "mulheres da vida", em um processo de monitoramento.

De acordo com Padilha, Borenstein e Santos (2011), a queda do Império Romano deixou brechas para a criação e aumento do charlatanismo, assim como o poderio da Igreja, havendo uma consequente redução da qualidade da medicina, em que seus cuidados são trocados por curandeiros e charlatões, marcando o início da Idade Média.

Na história da Grécia antiga, assim como na Roma antiga, não há claramente a figura de um cuidador, porém, em determinados escritos, hipocráticos e em estudos clínicos específicos, citados em livros, há relatos de auxiliares dos médicos, pois seria improvável conseguir tantos dados para resultar em evoluções completas, com vários dias de acompanhamento dos doentes, em que os mesmos ajudavam na aplicação de emplastos, compressas frias, dietas líquidas e banhos quentes (PADILHA; BORENSTEIN; SANTOS, 2011).

Conforme reiterado por Padilha, Borenstein e Santos (2011) um dos deuses cultuados pelos gregos era Apolo, deus do Sol, da Saúde, e da Medicina. Seu filho Esculápio foi considerado o principal curador da época da Guerra de Troia, sua representação é até hoje símbolo da medicina: a vara de Mercúrio juntamente com serpentes entrelaçadas. Segundo a literatura, seu filho, Macaón, era um exemplar cirurgião e sua nora, Epígona, a reconfortadora dos enfermos; suas netas, Higia e Panaceia, eram a deusa da saúde e a restauradora da saúde, respectivamente.

Padilha, Borenstein e Santos (2011) escrevem que os templos eram famosos locais de cura, além de acomodar visitantes, com: banheiros, casa para sacerdotes e médicos, bibliotecas etc. Epidauros é um exemplo, que abrigava até 500 pacientes, em que os tratamentos eram à base de banhos, proibição de alguns alimentos e vinhos, além de rituais religiosos, hipnotismo, dentre outras técnicas. Contudo, outros lugares que tratavam dos doentes eram conhecidos por chenodochium (possivelmente deu origem ao primeiro hospital contemporâneo) e iatrion (ambulatório dos enfermos). 
Todavia, a sociedade grega teve um relevante progresso com relação à saúde com a vinda da Filosofia, com real destaque a Aristóteles (348-322 a. C.), com suas teorias da biologia vegetal e animal e da anatomia, bem como por seus assuntos acerca da abordagem ética na forma científica (PADILHA; BORENSTEIN; SANTOS, 2011).

Dentro das concepções de Padilha, Borenstein e Santos (2011), Hipócrates de Cós (460-370 a. C.) foi considerado o "Pai da medicina" e da epidemiologia antiga. Segundo o filósofo, o profissional médico deveria usar elementos da natureza a fim de tratar seus doentes. De acordo com a literatura, há citações de Hipócrates na biblioteca de Alexandria - vista no filme Alexandria (2009) com relação a: tuberculose, epilepsia, malária, úlceras, epidemias e outras. Ademais, relatava a importância do exame do enfermo, buscando o tratamento e alimentação ideais, pautado na investigação clínica.

Reiterado pela literatura, Hipócrates baseava os tratamentos dos desequilíbrios humorais (quatro humores: sangue, catarro, bílis negra e bílis amarela), ou seja, da doença, com quatro elementos - água, terra, fogo e ar. Tinha como princípios a observação do indivíduo no estado de enfermidade, buscando fazer sua evolução, relatava as condições propícias a uma doença endêmica e epidêmica, aliado à ética profissional (PADILHA; BORENSTEIN; SANTOS, 2011).

De acordo com Padilha, Borenstein e Santos (2011), havia resquícios de relatos da existência de enfermeiros, e, mesmo assim, eles eram homens, cabendo às mulheres cuidar de crianças, serem amas e parteiras (os médicos só realizavam partos mediante alguma anormalidade ou complexidade). Nos cardíacos os enfermeiros cuidavam da alimentação regrada e em casos renais, da ingestão de altas quantidades de líquidos.

Também havia uma preocupação que, provavelmente, foi a precursora dos princípios higienistas: limpeza dental, limpeza das roupas e camas etc. Isso é: a doença não se originava de coisas sobrenaturais, mas sim pela não observância das leis naturais. Assim, o médico deveria ajudar o paciente a restaurar seu equilíbrio natural encontrando também um remédio natural, em que esse conhecimento possivelmente deu origem a profissão de enfermagem (PADILHA; BORENSTEIN; SANTOS, 2011).

Em suma, abordar o cuidado especificamente da Enfermagem na Antiguidade ainda é algo um tanto quan- to incompleto e misterioso da medicina antiga.

No que concerne ao último continente conhecido e explorado - a América -, e os povos que o habitavam: incas, maias, astecas e toltecas, havia um maior desenvolvimento com relação aos cuidados de Enfermagem e farmácia, que se misturaram às práticas de curandeiros (assim como pela sugestão do significado do próprio prefixo da palavra, eles tinham como função curar as doenças da mente e do corpo) (PADILHA; BORENSTEIN; SANTOS, 2011).

Como em outras civilizações, esse povo acreditava que as doenças ocorriam pela ira dos deuses e que a saúde era o equilíbrio do homem com a natureza e o sobrenatural. Entre os nativos americanos, a mulher tinha como função: cuidar das crianças, idosos e enfermos, bem como assistir aos partos. Havia a prática do sacrifício humano, e a crença de que a doença humana se transferiria para o animal sobrenaturalmente. Adotavam certos procedimentos como: jogar água sobre pedras vermelhas, usar substâncias aromáticas e bater com ramas no corpo para melhorar o processo circulatório (PADILHA; BORENSTEIN; SANTOS, 2011).

Já no caso de estudar a Idade Média, entrelaçada à Enfermagem com a intervenção de conteúdos fílmicos e investigação bibliográfica, como por exemplo, no filme Em nome de Deus (1988), seria uma viagem e um artifício favorável retratando a época em questão, ou seja, cerca de 1000 anos, proporcionando paisagens familiares aos estudantes, por exemplo, ao ver uma película sobre esse tempo e essa sociedade remota, fazendo considerações com relação à atualidade (PADILHA; BORENSTEIN; SANTOS, 2011).

Segundo Padilha, Borenstein e Santos (2011), a amplitude temporal do medievalismo é questionada, com a ausência de marcadores que identificassem de pronto tal período, bem como nas práticas de Enfermagem empreendidas durante a Idade Média, o que dificulta compreender a saúde diante dessa complexidade temporal (PADILHA; BORENSTEIN; SANTOS, 2011).

Contudo, sabe-se que a Igreja e o militarismo quase sempre estiveram ligados à Enfermagem. A primeira, sempre com enfoque ao cuidado por caridade, incentivando atos voltados aos pobres e enfermos, enquanto o segundo enfatizava o cuidado com relação aos feridos de guerra, trazendo à tona marcos da Enfermagem contemporânea. Já com relação às questões de gênero na Enfermagem, nessa época, segundo a literatura, a presença 
feminina foi marcante, principalmente como parteiras. Enfim, alguns cuidados realizados suplantavam os ideais de caridade impostos pela religião, dando início a uma certa cientificidade do cuidar (PADILHA; BORENSTEIN; SANTOS, 2011).

Configura-se um esquema de divisão de trabalho na saúde, diferenciando-se hierarquicamente o nível de cuidado/cuidador em cada profissão. A criação das universidades pode ser considerada uma forma de buscar, mesmo que vinculada à Igreja, uma maior cientificidade das práticas até então realizadas, como uma pequena expansão dos conhecimentos para além dos monastérios, como exemplo podemos citar o no filme O nome da rosa (1986).

Referente ao número e tamanho dos hospitais na Idade Média, segundo a literatura, eram grandes e desproporcionais comparados à demanda existente, e regidos conforme a normatização eclesiástica (PADILHA; BORENSTEIN; SANTOS, 2011).

Enquanto na Europa, já na Idade Moderna, houve uma implementação das ações em saúde, incluindo os cuidados de Enfermagem, as citações históricas indicam que no Brasil, ainda colônia de Portugal, o avanço foi tão ínfimo que ficou estagnado por cerca de 300 anos, pois as práticas de saúde eram empíricas e desenvolvidas somente por pessoas leigas. Assim como na Europa, a profissão médica já havia garantido seu status, a de Enfermagem, antes exercida majoritariamente por religiosos, passou a ser expandida como atividade de mulheres sem prestígio social (PADILHA; BORENSTEIN; SANTOS, 2011).

A consolidação da Enfermagem como profissão ocorre no final do século XIX, com destaque para a Inglaterra (em paralelo ao avanço do capitalismo e ascensão social da burguesia) e com grande influência de Florence Nightingale. A disciplina tornou-se um dos princípios da profissão, que passou a executar atividades no mesmo cenário e com os mesmos sujeitos que os médicos - o hospital e o paciente, respectivamente (PADILHA; BORENSTEIN; SANTOS, 2011).

No Brasil, após a vinda da família real portuguesa ao Brasil, e durante o século XIX, com o avanço urbano nas grandes cidades como Rio de Janeiro e São Paulo, por exemplo, nos deparamos com uma falta de organização na saúde pública, favorecendo a disseminação de doenças como: a peste bubônica, a varíola e a febre amarela. Há na história citações de diversas intervenções de médicos sanitaristas, engenheiros e enfermeiros (num contexto de polícia sanitária das cidades). É nesse contexto efervescente que, no final do século XIX, com a criação da Escola de Enfermeiras do Hospício Nacional de Alienados, em 1890, (e no início do século XX, da Escola de Enfermeiros do Departamento Nacional de Saúde Pública Brasil) podemos perceber um incipiente início de valorização da profissão (PADILHA; BORENSTEIN; SANTOS, 2011).

De acordo com a literatura, em 1892, Miss Nightingale já contava com 72 anos, e até a morte, ela sustentou que a Enfermagem era uma arte, uma vocação, e uma profissão. Ela se dedicou cerca de 50 anos ao ensino da enfermagem. Em consonância com os pensamentos de Rolka (1994), Nightingale foi incluída entre as 100 mulheres que marcaram a história mundial, tendo sua imagem associada à de uma heroína nacional. Também são de parecer de Padilha, Borenstein e Santos (2011), que o nome da enfermeira Florence Nightingale é associado às seguintes características: honestidade, sobriedade, religiosidade e devoção, habilidade de observação minuciosa, fidelidade e delicadeza, delineando aspectos que foram considerados essenciais à formação profissional.

Dentro das concepções de Nelson e Rafferty (2010), essa notoriedade foi basilar na criação dos primeiros cursos de Enfermagem pautados no sistema nightingaliano.

No decorrer da História, após a sindicalização dos profissionais de Enfermagem, a década de 1950 revela o processo de cientificização da profissão no mundo. No Brasil, por exemplo, discute-se a divisão do processo de trabalho em intelectual e prático, administrativo e técnico, bem como da própria divisão da categoria em classes dicotomizadas (PADILHA; BORENSTEIN; SANTOS, 2011).

Já no final do século XX e início do século XXI, mais especificamente nas décadas de 1990 e 2000, foram marcos temporais de transformações nos setores político, econômico, social, bem como na saúde e na enfermagem, enquanto prática social inserida nesse contexto, período verificado no avanço distorcido ou não da ciência nos seguintes filmes: O jardineiro fiel (2005), Código de honra (2011), Uma lição de vida (2001), O óleo de Lorenzo (1992) entre outros. 


\section{Considerações Finais}

Estudos sobre a História da Enfermagem se encontram em processo de sedimentação. É possível reconhecer as limitações quantitativas na produção científica dessa temática a nível nacional. Porém percebe-se um aumento dos estudos de natureza sócio histórica, particularmente no reconhecimento dos saberes constituintes dos contextos históricos e culturais da área (PADILHA, 2004 apud PADILHA; BORENSTEIN; SANTOS, 2011).

Nessa perspectiva, estudos historiográficos são imprescindíveis para a construção do conhecimento da Enfermagem, sendo que a utilização do cinema, como fonte de pesquisa, é uma possibilidade concreta.

Corrobora-se com Rosenstone (2010) na perspectiva de que as mídias visuais são importante agente transmissor da história pública de nossa cultura, bem como, segundo o autor, parece "sensato" reconhecer que nossa sociedade tem sua consciência histórica moldada por estas mídias, mesmo que os filmes sejam reflexo direto das interpretações da época de sua produção.

Espera-se contribuir, por meio dessas reflexões, na construção de um perfil profissional inovador, subsidiando uma aprendizagem mais dinâmica, imbuída de qualidade ao mediar práticas sociais e culturais; estimulando e favorecendo a formação de Enfermeiros contextualizada na sua historicidade e dinamicidade.

\section{Referências}

A GUERRA do fogo. Direção de Jean-Jacques Annaud. França: Belstar Productions, 1981. 1 DVD (100 min), color.

ABUD, Katia Maria. A construção de uma didática da História: algumas ideias sobre a utilização de filmes no ensino. História, São Paulo, v. 22, n. 1, p. 183-192, 2003. Disponível em: <http://www.scielo.br/pdf/his/v22n1/ v22n1a08.pdf >. Acesso em: 02 out. 2012.

ALEXANDRIA. Direção de Alexandro Amenábar. Espanha: Mod Producciones, 2009. 1 DVD (127 min), color.

BÍBLIA, A. T. Gênesis. Biblia Sagrada. 42. ed. São Paulo: Ave Maria, 1982. cap. 24.

CLEÓPATRA. Direção de Joseph Mankiewicz. Inglaterra: Twentieth Century Fox Film Corporation, 1963. 1 DVD (243 min), color.

CÓDIGO de honra. Direção de Adam Kassen e Mark Kassen. EUA: Paramount Pictures, 2011. 1 DVD (100 $\min$ ), color.
DANTAS, Anielle Avelina; MARTINS, Carlos Henrique; MILITÃO, Maria Socorro Ramos. O Cinema como instrumento didático para a abordagem de problemas bioéticos: uma reflexão sobre a eutanásia. Revista Brasileira de Educação Médica, Rio de Janeiro, v. 35, n. 1, p. 69-76, jan./ mar. 2011. Disponível em: <http://www.scielo.br/scielo. php?pid $=$ S0100-55022011000100010\&script $=$ sci_art text>. Acesso em: 15 ago. 2012.

EM NOME de Deus. Direção de Clive Donner. Reino Unido: Scottish Screen, 1988. 1 DVD (115 min), color.

FERRO, Marc. Cinema e história. São Paulo: Paz e Terra, 2010.

FISCHER, Rosa Maria Bueno. Mídia, máquinas de imagens e práticas pedagógicas. Revista Brasileira de Educação, v. 12, n. 35, p. 290-299, maio/ago. 2007. Disponível em: <http://www.scielo.br/scielo.php?pi$\mathrm{d}=$ S1413-24782007000200009\&script=sci_abstract\&tln$\mathrm{g}=\mathrm{pt}>$. Acesso em: 16 ago. 2012.

KEELING, Arlene. Position paper on history in curriculum: preparing nurses for the 21 st. century. 21 sept. 2001. Disponível em: <http://aahn.org/position.html >. Acesso em: 15 jun. 2012.

MARTINS, Ana Paula (Coord.) et al. O cinema na sala de aula: uma abordagem didática. Curitiba: UFPR, PET-História, 2008.

NAPOLITANO, Marcos. Como usar o cinema na sala de aula. São Paulo: Contexto, 2010.

MORAIS, Ronaldo Queiroz de. Na prática docente a teoria se desmancha no ar: a resistência a teoria no espaço-escolar. Educação, v. 29, n. 01, p. 37-47, jan/jun. 2004. Disponível em: <http://cascavel.ufsm.br/revistas/ojs-2.2.2/ index.php/reveducacao/article/download/3869/2232>. Acesso em: 20 ago. 2012.

RIBEIRO, Thiago. Civilização grega. 2008. Disponível em: <http://www.mundoeducacao.com.br/historiageral/ civilizacao-grega.htm>. Acesso em: 10 jul. 2012.

NELSON, Sioban; RAFFERTY, Anne Marie. Notes on Nightingale: the influence and legacy of a nursing icon. New York: Cornell University Press, 2010. Disponível em: $<$ digitalcommons.ilr.cornell.edu/cgi/viewcontent.cgi?article $=1060>$. Acesso em: 20 ago. 2012.

O JARDINEIRO fiel. Direção de Fernando Meirelles. Alemanha: Potboiler Productions, 2005. 1 DVD (128 $\min$ ), color.

O NOME da rosa. Direção de Jean-Jacques Annaud. Alemanha Cristaldifilm, 1986. 1 DVD (130 min), color. 
O ÓLEO de Lorenzo. Direção de George Miller. EUA: Universal Pictures, 1992. 1 DVD (129 min), color.

OGUISSO, Taka. Trajetória histórica e legal da enfermagem. 2. ed. Barueri: Manole, 2007.

PADILHA, Maria Itayra Coelho de Souza. O resgate das raizes: a influência da formação familiar e social na escolha e no exercício da enfermagem. 1991. Tese (Livre-docência) - Escola de Enfermagem Alfredo Pinto, Unirio, 1991.

PADILHA, Maria Itayra Coelho de Souza. A instrumentalização de docentes para o ensino da história da enfermagem nos cursos de graduação do Estado de Santa Catarina. Florianópolis: UFSC, 2004. Projeto em desenvolvimento, aprovado pelo CNPq.

PADILHA, Maria Itayra; BORENSTEIN, Miriam Süskind; SANTOS, Iraci dos. Enfermagem: história de uma profissão. São Caetano do Sul: Difusão, 2011.

PEREIRA, Lara Rodrigues. A abordagem didática do uso do cinema em sala de aula. Colóquio "Ensino médio, história e cidadania”, v. 1, n. 1, p. 1-10, 2011. Disponível em: $<$ http://www.periodicos.udesc.br/index.php/EnsinoMedio/article/view/2342>. Acesso em: 02 jul. 2012.
ROSENSTONE, Robert A. Ver o passado. In: . $A$ história nos filmes: os filmes na história. São Paulo: Paz e Terra, 2010. p. 27-54.

SILVA, Carmen Maria dos Santos Lopes Monteiro Dantas da; SANTOS, Neiva Maria Picinini. A imagem da teoria e da prática de enfermagem em filmes: uma análise à luz dos depoimentos dos estudantes. Revista Cogitare Enfermagem, Curitiba, v. 14, n. 2, p. 332-339, abr./jun. 2009. Disponível em: <http://ojs.c3sl.ufpr.br/ojs2/index.php/ cogitare/article/download/15626/10397>. Acesso em: 02 jul. 2012.

TOURINHO, Maria Antonieta; VIEIRA, Rosane. História e cinema na escola. Rumores, São Paulo, v. 5, n. 10, p. 154-165, jul./dez. 2011. Disponível em: <http://www.revistas.usp.br/Rumores/article/view/51257/55327>. Acesso em: 02 jul. 2012.

UMA LIÇÃO de vida. Direção de Mike Nichols. EUA: BBC Films, 2001. 1 DVD (99 min), color.

VIEIRA, Ana Thereza. Basilio. O médico e a medicina em Roma. 2008. Disponível em: <http://www.letras.ufrj.br/ pgclassicas/medicinaana.pdf>. Acesso em: 11 jul. 2012. 